\title{
Pattern of gynecological malignancies in south Punjab Region of Pakistan: An overview of 5 years.
}

1. FCPS (Obs \& Gynae) Assistant Professor Gynecology Nishtar Medical University, Multan

2. FCPS (Oncology)

Head Oncology

Nishtar Medical University, Multan.

3. FCPS (Obs \& Gynae)

Head Gynae Unit

Nishtar Medical University, Multan

Correspondence Address:

Dr. Shagufta Tabassum

Department of Gynecology

Nishtar Medical University, Multan

dr.shaguftatabassum@hotmail.com

Article received on:

18/03/2020

Accepted for publication:

$24 / 06 / 2020$

\section{Shagufta Tabassum ${ }^{1}$, Ahmed ljaz Masood ${ }^{2}$, Mehnaz Khakwani ${ }^{3}$}

ABSTRACT... Objectives: To find out the pattern of female gynecological malignancies in Pakistan, with the aim of providing basis for the development of preventive strategies to combat the current trend. Study Design: Observational study. Setting: Department of Oncology, Nishtar Medical University, Multan, Pakistan. Period: $1^{\text {st }}$ January 2015 to $31^{\text {st }}$ December 2019. Material \& Methods: A retrospective analysis of all the cases of female gynecological malignancies presented was carried out using a proforma. The data was analyzed using frequencies and percentages. Results: The gynecological malignancies are the fourth (20.64\%) most common female malignancies. Among gynecological cancers; ovarian cancer (47.1\%) is the commonest, followed by cervical cancer $(24.8 \%)$, uterine cancer $(11.6 \%)$, gestational trophoblastic neoplasia (12.9\%), vaginal cancer $(2 \%)$ and vulval cancer (1.6\%). Conclusion: Gynecological malignancies constitute a major portion of female malignancies. The need of the hour is to design effective preventive and control strategies, so as to lower the burden of female gynecological malignancies in future.

Key words:

Female Gynecological Malignancies, Overview, Pattern.

Article Citation: Tabassum S, Masood Al, Khakwani M. Pattern of gynecological malignancies in south Punjab Region of Pakistan: An overview of 5 years. Professional Med J 2021; 28(1):90-95. https://doi.org/10.29309/TPMJ/2021.28.01.4665

\section{INTRODUCTION}

The gynecological malignancy is the uncontrolled growth of abnormal cells that originate from the reproductive organs and spread to nearby tissues. In United States, a new case of gynecological malignancy is diagnosed every sixth minute. Out of every 400 persons (per 100,000 population) who are diagnosed with any of more than 100 types of malignancies, $12 \%$ have a female reproductive organs related malignancy. ${ }^{1}$ Gynecological malignancies involve the genital tract and include those of the ovary, cervix, uterus, vulva, vagina and gestational trophoblastic malignancies. The gynecological cancers enroll themselves as the leading cause of malignancy-related mortalities across the world. $^{2}$ The incidence, prevalence and mortality rates vary widely among different gynecological cancers.

The pattern of gynecological malignancies reflects variations across different geographical regions owing to differences in genetic pattern, environment, lifestyle, dietary habits, socioeconomic background, education, awareness, health care system and screening etc. ${ }^{3}$ Gynecological cancers are no doubt the most common cancers in women. ${ }^{4}$ Their frequency and distribution vary among different countries. ${ }^{5}$ In affluent countries, endometrial cancer is the most common gynaecological malignancy, where as in developing countries, it is the cervical cancer that is predominantly encountered. ${ }^{6}$

Worldwide, cervical cancer predominates as the most common gynecological malignancy. ${ }^{7}$ It accounts for around $10 \%$ of all malignancies in women $^{8}$, with $85 \%$ cases in less developed world due to lack of established screening programmes. ${ }^{9}$ It has a long natural history, incorporating a prolonged pre-cancerous phase that is not only detectable but also treatable. Its incidence has considerably decreased in affluent societies as a consequence of proper screening programs and availability of HPV vaccines. 
Endometrial cancer constitutes the dominant gynecological malignancy of developed countries where incidence is four times higher than in developing countries. ${ }^{10}$ This increase is attributable to obesity, increased life expectancy and tamoxifen use for breast cancer.

Among all gynecological cancers, the most lethal is ovarian cancer. This is attributable to its insidious presentation along with molecular and histological variabilities. In England, ovarian cancer is the second commonest malignancy after uterine cancer but accounts for more life losses than all other gynecological malignancies taken together. ${ }^{11}$

Gestational trophoblastic disease encompasses a range of gestation-related diseases extending from the benign condition of hydatidiform mole to the malignant conditions of choriocarcinoma, invasive mole and placental-site trophoblastic tumor. The availability of a highly sensitive tumor marker in the form of beta Human Chorionic Gonadotropin along with the highly chemosensitive nature of the disease and the availability of efficacious chemotherapy has resulted in marvellous survival rates, which are in excess of $98 \% .^{12}$

This article has been written to get insight into the pattern of various gynecological malignancies in Pakistan. A retrospective analysis of gynecological cancers identified at Oncology Department, Nishtar Medical University Multan, Pakistan over the last 5 years (January 2015 - December 2019) was carried out. Their relative frequencies were studied to establish a database. A comparison of this data was made with that available from national and international studies. This data will be helpful to counter the gynecological malignancy peril through actions like screening programs, health education and appropriate allocation of resources.

\section{MATERIAL \& METHODS}

The medical records of all the patients presented in Oncology Department, Nishtar Medical University Multan, during the study period were analyzed to identify those with female gynecological malignancies. The study covered a period of 5 years from 1st January 2015 to 31st December 2019. The case records of all patients presented to the Oncology Department with suspected gynecological malignancy were retrieved from the medical records department. The demographic information was collected using a proforma. Only those cases were included which had confirmed histological diagnosis. The cases of choriocarcinoma were diagnosed on clinical features and confirmed by biochemical tests and ultrasonography. The patients with benign gynecological tumors were excluded from the study. The data was analyzed using percentages and frequencies. Ethical approval for the study was obtained from the Ethical and research review committee of Nishtar Medical University, Multan.

\section{RESULTS}

During the study period of five years, 6163 total (male \& female) patients presented to Oncology department with confirmed malignancies. Out of these, $3106(50.4 \%)$ were female patients. The most common female malignancy was breast carcinoma, followed by leukemia, colorectal cancer and gynecological malignancy. Gynecological malignancy constituted $20.64 \%$ of all female malignancies.

\begin{tabular}{|c|c|c|c|}
\hline Year & $\begin{array}{c}\text { No of Females } \\
\text { Patients }\end{array}$ & $\begin{array}{c}\text { No. of Females with } \\
\text { Gynecological Malignancy }\end{array}$ & $\begin{array}{c}\text { \%age of Females with } \\
\text { Gynecological Malignancy }\end{array}$ \\
\hline 2015 & 723 & 155 & 21.4 \\
\hline 2016 & 656 & 135 & 20.6 \\
\hline 2017 & 627 & 121 & 19.3 \\
\hline 2018 & 502 & 112 & 22.3 \\
\hline 2019 & 598 & 117 & 19.6 \\
\hline Average/year & 621 & 128 & 20.64 \\
\hline
\end{tabular}

Table-I. Female gynecological malignancies with regard to total female malignancies 


\begin{tabular}{|c|c|c|c|c|c|c|c|}
\hline Year & $\begin{array}{c}\text { Total Female } \\
\text { Gynecological } \\
\text { Cancers }\end{array}$ & $\begin{array}{c}\text { Uterine } \\
\text { Cancer }\end{array}$ & $\begin{array}{c}\text { Ovarian } \\
\text { Cancer }\end{array}$ & $\begin{array}{c}\text { Cervical } \\
\text { Cancer }\end{array}$ & $\begin{array}{c}\text { Vulval } \\
\text { Cancer }\end{array}$ & $\begin{array}{c}\text { Vaginal } \\
\text { Cancer }\end{array}$ \\
\hline 2015 & 155 & $14(9 \%)$ & $77(49.7 \%)$ & $42(27.1 \%)$ & $4(2.6 \%)$ & $4(2.6 \%)$ \\
\hline 2016 & 135 & $13(9.6 \%)$ & $54(40 \%)$ & $38(28.1 \%)$ & $3(2.2 \%)$ & $3(2.2 \%)$ & $24(17.8 \%)$ \\
\hline 2017 & 121 & $20(16.5 \%)$ & $54(44.6 \%)$ & $26(21.5 \%)$ & $3(2.5 \%)$ & $1(0.8 \%)$ \\
\hline 2018 & 112 & $17(15.2 \%)$ & $56(50 \%)$ & $26(23.2 \%)$ & $0(0 \%)$ & $2(1.8 \%)$ & $17(14 \%)$ \\
\hline 2019 & 117 & $9(7.7 \%)$ & $60(51.3 \%)$ & $28(23.9 \%)$ & $1(0.8 \%)$ & $3(2.6 \%)$ & $16(13.7 \%)$ \\
\hline Disease
\end{tabular}

\section{DISCUSSION}

Gynecological oncology is a specialized field of medicine that pivots on cancers of the female reproductive system, including cervical cancer, uterine cancer, ovarian cancer, vaginal cancer, vulvar cancer and gestational trophoblastic tumors. Though often grouped together, each gynecologic cancer has distinct symptoms, signs, risk factors, prognosis, diagnostic strategies and management options. The burden of gynecological malignancies is increasing worldwide, but the main rise is in developing as compared to developed countries, with approximately five million new cancer cases being diagnosed each annum. ${ }^{13}$ The prognosis varies widely among different gynaecological malignancies and predominantly depends on the stage of the malignancy at the time of the diagnosis.

According to World Health Organization, cancer dilemma is dramatically peaking in developing countries especially the third world areas. Despite widespread awareness campaigns about the importance of screening for earlier detection and treatment of gynecologic cancers, studies suggest that numerous disparities exist in the quality of care for these diseases, particularly regarding to race, socioeconomic status and educational level. ${ }^{14}$ Overall, it seems that inaccessibility to standard care for gynecologic cancers is the major contributing factor to healthcare disparities in this field; particularly in developing countries like our country-Pakistan.

Nishtar Medical University is a public sector Health Sciences University located in Multan city of Punjab province in Pakistan. It is one of the most prestigious world known medical institutions of Pakistan which provides medical coverage not only to south Punjab but also central Punjab and many areas of adjacent provinces. Our study was conducted in the Oncology department of this institution. The reason for selecting oncology department instead of our gynecological unit is that our gynecological unit covers only those patients who are admitted in our ward; while oncology department receives gynecological malignancies patients not only from all the units of Nishtar Medical University but also from the public and private sector of all nearby cities and adjacent areas of other provinces.

In our study, gynecological malignancies have stoodfourth amongallfemale cancers, constituting $20.64 \%$ of all female malignancy burdens. This is high as compared to International studies, where gynecological cancers occupy about $12 \%$ of all female cancers. This difference can be explained by the fact that our women have little access to healthcare facilities, lack of structured screening programs, low socio-economic status as well as lack of education. The consequence is the progression of benign cases to malignancy, even then presenting in late stages.

In our study, ovarian carcinoma turned out to be the most common female gynecological malignancy which is comparable to other local studies. Almost similar results $(48 \%)$ were found by Manzoor $\mathrm{H}$ et al in a study conducted in Pakistan. ${ }^{15}$ Though it is more common in developed countries but the incidence is quite high in our study of developing country and might be the result of new trends in lifestyle which act as contributing factors like late conception, short families and 
lack of breast feeding. ${ }^{16}$ Also the dietary habits of our population have changed tremendously over the last decade and this in combination with reduced physical activity has contributed to weigh gain in our female population. Obesity is clearly linked to rising trends of ovarian cancer. ${ }^{17}$ The lifetime risk of a woman harboring ovarian cancer is $1: 75$, while her chance of dying of the disease is $1: 100 .{ }^{18}$ Ovarian cancer is no doubt the most fatal of all gynecological malignancies; the reason being its insidious presentation and vast variations in molecular and histological basis. Due to non-significant symptoms, patient usually presents late or the diagnosis is delayed. Till that time, the malignancy has spread beyond local region, making treatment less fruitful and the prognosis progressing to worse situations. It has often been known as a "silent killer". Late stage diagnosis results in prolonged, complex, costly and aggressive treatment; thus posing a great challenge in developing countries. ${ }^{19}$ Though serial ultrasonography and CA 125 have been proposed as screening test, but still have not proved to be beneficial. ${ }^{20}$

Cervical cancer ranked second in our study, constituting $27 \%$ of female gynecological malignancies. This result differs from other international studies which claim cervical cancer to be the most prevalent female gynecological malignancy of developing countries. This disparity can be attributed to the differences in religious backgrounds which affects the sexual behavior of our study population. The women in our region engage in monogamous relations, thereby decreasing the likelihood of HPV infection and consequential cervical cancer. ${ }^{21}$ Though the incidence is relatively less, but the mortality from cervical cancer is quite high. This is the consequence of lack of a structured screening process, scarcity of awareness about HPV vaccination, lack of follow up and late presentation. Even educated people in our country are not much aware of cervical screening by Pap smear and HPV vaccination availability ${ }^{22}$, as HPV is the leading cause of cervical cancer in Pakistani women. ${ }^{23}$ third in the list of gynecological malignancy. This is similar to the study conducted in India by Badar $\mathrm{F}$ et al. ${ }^{24}$ Abnormal vaginal bleeding is the pathognomonic feature of uterine cancer and timely evaluation of this symptom can increase the likelihood that uterine cancer is not only diagnosed earlier but also treated appropriately within safe time limits. ${ }^{25}$

The next common malignancy is Gestational Trophoblastic Neoplasia. The incidence in our study is high as compared to international studies. This can be the result of the fact that our country people belong to low socio-economic status and this disease is linked with the poverty. Moreover, it is highly chemo-sensitive and almost all patients are referred to Oncology Department with full faith for almost complete recovery, leading to relatively higher rates in our study.

Vaginal and vulval cancers comprise $2 \%$ and $1.6 \%$ respectively of all gynecological cancers. The incidence is low relative to international studies ${ }^{26}$, which might be due to improved hygiene of the concerned area as is practiced by religious beliefs of local population.

\section{CONCLUSION}

The gynecological malignancy is the fourth leading malignancy among women population of our area. The need of the hour is to develop awareness about the screening program, HPV vaccination and early referral for warning symptoms and signs; so that the disease can be prevented or diagnosed early and treated appropriately.

Copyright (C) 24 June, 2020.

\section{REFERENCES}

1. Pal S, Incidence of Gynecological Cancers, US Pharm. 2014; 39(9):11.

2. Basile S, Angioli R, Manci N, Palaia I, Plotti F, Benedetti Panici P. Gynecological cancers in developing countries: The challenge of chemotherapy in lowresources setting. Int J Gynecol Cancer. 2006; 16:1491-1497. doi: 10.1111/j.1525-1438.2006.00619.x. [PubMed] [CrossRef] [Google Scholar]. 
3. Stewart BW, Kleihues P, editors. World Cancer Report. IARC Press; Lyon, France: 2003. pp. 1-342. [Google Scholar].

4. Maheshwari A, Kumar N, Mahantshetty U. Gynecological cancers: A summary of published Indian data. South Asian J Cancer. 2016; 5(3):112-20.

5. Rahman MA, Siddika ST, Mazid MA. Gynaecological Cancers in Surgical Specimens A Hospital Based Analysis. Medicine Today. 2014;26(2):78-82. https:// doi.org/10.3329/medtoday.v26i2.24225.

6. Rahman MA, Siddika ST, Mazid MA. Gynaecological cancers in surgical specimens A Hospital Based Analysis. Medicine Today. 2014; 26(2):78-82.

7. Torre LA, Bray F, Siegel RL, Ferlay J, Lortet-Tieulent J, Jemal A. Global cancer statistics, 2012. CA: A cancer journal for clinicians. 2015 Mar; 65(2):87-108.

8. Daniyal M, Akhtar N, Ahmad S, Fatima U, Akram M, Asif HM. Update knowledge on cervical cancer incidence and prevalence in Asia. Asian Pac J Cancer Prev. 2015 Jun 18; 16(9):3617-20.

9. Bermudez A, Bhatla N, Leung E. Cancer of the cervix uteri. International Journal of Gynecology \& Obstetrics. 2015 Oct; 131:S88-95.

10. Ferlay J, Autier P, Boniol M, Heanue M, Colombet M, Boyle P. Estimates of the cancer incidence and mortality in Europe in 2006. Annals of oncology. 2007 Mar 1;18(3):581-92.

11. Doufekas K, Olaitan A. Clinical epidemiology of epithelial ovarian cancer in the UK. International journal of women's health. 2014; 6:537.

12. Froeling FE, Seckl MJ. Gestational trophoblastic tumours: An update for 2014. Current oncology reports. 2014 Nov 1; 16(11):408.

13. Crane K. Palliative care gains ground in developing countries. J Natl Cancer Inst. 2010 Nov 3; doi: 10.1093/ jnci/djq445. (Epub ahead of print).

14. Collins Y, Holcombe K, Chapman-Davis E, Khalebe D, Farley JH. Gynecologic cancer disparities: A report from the Health Disparities Taskforce of the Society of Gynecologic Oncology. Gynecol Oncol. 2014; 133:353-361.

15. Manzoor $H$, Naheed $H$, Ahmad $K$, Iftikhar $S$, Asif M, Shuja J, Sultan N, Ali I, Inayatullah S, Khan YH. Pattern of gynaecological malignancies in south western region of Pakistan: An overview of 12 years. Biomedical reports. 2017 Nov 1; 7(5):487-91.
16. Li DP, Du C, Zhang ZM, Li GX, Yu ZF, Wang X, Li PF, Cheng $C$, Liu YP, Zhao YS. Breastfeeding and ovarian cancer risk: A systematic review and meta-analysis of $\mathbf{4 0}$ epidemiological studies. Asian Pac J Cancer Prev. 2014 Jan 1; 15(12):4829-37.

17. Liu Z, Zhang TT, Zhao JJ, Qi SF, Du P, Liu DW, Tian QB. The association between overweight, obesity and ovarian cancer: A meta-analysis. Japanese journal of clinical oncology. 2015 Oct 21 ; 45(12):1107-15.

18. Howlader N, Noone AM, Krapcho M, Neyman N, Aminou R, Waldron W, et al. SEER Cancer Statistics Review, 1975-2008, National Cancer Institute. Bethesa, MD, http://seer.cancer.gov/csr/1975_2008/, based on November 2010 SEER data submission, posted to the SEER web site, 2011.

19. Aniebue UU, Onyeka TC. Ethical, socioeconomic, and cultural considerations in gynecologic cancer care in developing countries. Int J Palliat Nurs 2014. 2014:141627. doi:10.1155/2014/141627. [Google Scholar.

20. Henderson JT, Webber EM, Sawaya GF. Screening for ovarian cancer: updated evidence report and systematic review for the US preventive services task force. Jama. 2018 Feb 13; 319(6):595-606.

21. Bibi S, Ashfaque S, Laghari NA. A heartrending burden of gynaecological cancers in advance stage at nuclear institute of medicine and radiotherapy Jamshoro Sindh. Pak J Med Sci. 2016; 32:120-124. [PMC free article] [PubMed] [Google Scholar].

22. Aziz N, Yousfani S. Pattern of presentation of cervical carcinoma at Nuclear Institute of Medicine and Radiotherapy, Pakistan. Pak J Med Sci. 2013; 29:814817. [PMC free article] [PubMed] [Google Scholar].

23. Raza SA, Franceschi S, Pallardy S, Malik FR, Avan BI, Zafar A, Ali SH, Pervez S, Serajuddaula S, Snijders PJ, et al. Human papillomavirus infection in women with and without cervical cancer in Karachi, Pakistan. $\mathrm{Br} J$ Cancer. 2010; 102:1657-1660. doi: 10.1038/ sj.bjc.6605664. [PMC free article] [PubMed] [CrossRef] [Google Scholar.

24. Badar F, Mahmood S, Yusuf MA, Sultan F. Epidemiology of cancers in Lahore, Pakistan, 2010-2012: A crosssectional study. BMJ Open. 2016; 6:e011828. doi: 10.1136/bmjopen-2016-011828. [PMC free article] [PubMed] [CrossRef] [Google Scholar].

25. Henley SJ, Miller JW, Dowling NF, Benard VB, Richardson LC. Uterine cancer incidence and mortality-United States, 1999-2016. Morbidity and Mortality Weekly Report. 2018 Dec 7; 67(48):1333. 
AUTHORSHIP AND CONTRIBUTION DECLARATION

\begin{tabular}{|c|l|l|l|}
\hline Sr. \# & Author(s) Full Name & \multicolumn{1}{|c|}{ Contribution to the paper } & Author(s) Signature \\
\hline 1 & Shagufta Tabassum & $\begin{array}{l}\text { Data collection, Study design, } \\
\text { Interpretation, Principal investigator. } \\
\text { Data collection, Final reading. }\end{array}$ \\
\hline 3 & Ahmed ljaz Masood & Mehnaz Khakwani & Study design, Interpretation. \\
\hline
\end{tabular}

